\title{
Physiological and genetic aspects of a diploid potato population in the Netherlands and Northern Finland
}

\author{
Zaban, A. ${ }^{1)}$, Veteläinen, $\mathbf{M}^{12}{ }_{2}$ Celis-Gamboa, C. B. ${ }^{2)}$, Berloo, R van ${ }^{2),}$ Häggman, H. $^{3)}$ \& Visser, R. G. \\ $\mathrm{F}^{2)}$ \\ 1) MTT AgriFood Research Finland, North Ostrobothnia Research Station, Tutkimusasemantie 15, \\ 92400 Ruukki, Finland \\ ${ }^{2)}$ Wageningen University, Laboratory of Plant Breeding, P.O. Box 386, 6700 AJ Wageningen, The \\ Netherlands \\ ${ }^{3)}$ University of Oulu, Department of Biology, P.O.Box 3000, 90014 University of Oulu, Finland
}

\begin{abstract}
Tuberization of potatoes exposed to different photoperiod regimes has been earlier investigated in several studies. However, there is still a limited understanding of the entire tuberization process and the factors influencing this process. One of the constraints of the previous studies has been the use of only one or a few genotypes. Furthermore, the experimental designs have not utilised the natural growing conditions with continuous changes in day-length during the growing season. The general aim of the project was to study the developmental dynamics of the broad-based potato (Solanum tuberosum L.) (CxE) population development at different climatical regimes under the very long-day, long-day and short conditions in Finland, the Netherlands and Ecuador/Venezuela, respectively. In this paper we are presenting some of the results achieved in the studies in Finland during the growing season 2004. In addition to population level trait characteristics we also describe here some of the identified QTLs (quantitative trait loci) for stolon related and tuber formation traits. In some cases we also compare the expression of some of the traits both in Finland and Netherlands.

The main difference between the CxE population grown in Finland and the Netherlands was that the onset of flowering took place one week later in Finland. The relationship between tuber initiation and onset of flowering differed depending on the day length. In Finland approximately $70 \%$ of the genotypes had swollen stolon tips before the onset of flowering, while in the Netherlands only $30 \%$ of the genotypes had reached this condition. We also found numerous different trait linked QTLs, for example, a QTL associated with tuber formation was identified on chromosome E5, and QTLs associated with stolon characteristics on chromosomes E1, E4, E10 and E12. As a conclusion, the present preliminary results provide a good basis for determining the influence of different environmental conditions on potato development. In addition, the QTLs obtained in this study give a better understanding of the genetics of complex characters, and can be used in improving the potato crop in breeding programs.
\end{abstract}

\section{Key words}

Potato, flowering, tuberization, day length, QTLs 


\section{Introduction}

Tuberization of potatoes exposed to different photoperiod regimes has been earlier investigated in several studies (Werner 1942, Driwer \& Hawkes 1943, Mendoza \& Haynes 1976, Ewing 1978, Regel \& Sands 1983, Khedher \& Ewing 1985, Martinez-Garcia et al 2002). However, there is still a limited understanding of the entire tuberization process and factors influencing this process. One of the constraints of the previous studies has been the use of only one or a few genotypes. Furthermore, the experimental designs have not utilised the natural growing conditions with continuous changes in daylength during the growing season.

The general aim of the project is to compare the dynamics of the genetically broad based potato population development in Finland, the Netherlands and Ecuador / Venezuela in order to gain understanding on how different environmental conditions, especially day length, affect expression of various traits. In this paper we are presenting some of the results achieved in the studies in Finland during the growing season 2004. In addition to population level trait characteristics we also describe here some of the identified QTLs (quantitative trait loci) for stolon related and tuber formation traits. The QTL analyses were done in order to gain more knowledge on the genetics of these traits, to examine their expression at different developmental stages, and to investigate the potential environmental impact. The analyses were realised due to the existing molecular marker data produced at the Laboratory of Plant Breeding in Wageningen University. In some cases we were also able to compare the expression of some of the traits both in Finland and Netherlands.

\section{Material and methods}

The diploid backcross population termed "CxE" with 232 genotypes and 20 tetraploid cultivars which were used as controls, which are typically grown either in the Netherlands or in Finland, were supplied by the Laboratory of Plant Breeding, Wageningen University for the field experiments. The parental clone C is a hybrid between S. phureja PI225696.1 and S. tuberosum dihaploid USW42, while the parental clone $\mathrm{E}$ is the result of a cross between clone $\mathrm{C}$ and the $S$. vernei-S. tuberosum backcross clone $\mathrm{VH}^{3} 4211$ (Celis-Gamboa et al 2002, 2003, Celis Gamboa 2002).

In this paper we are presenting mainly results from the field experiment conducted at the North Ostrobothnia Research Station in Ruukki $\left(64^{\circ} 42^{\prime}\right.$ N, $25^{\circ} 00^{\prime}$ E) in 2004, but also from the previous corresponding experiment carried out in the Netherlands ( $51^{\circ} 58^{\prime} \mathrm{N}, 5^{\circ} 38^{\prime} \mathrm{E}$ ) in 1999. AFLP markers and map, which were generated and constructed by Celis-Gamboa (2002) on the CxE population, were used in the QTL analyses.

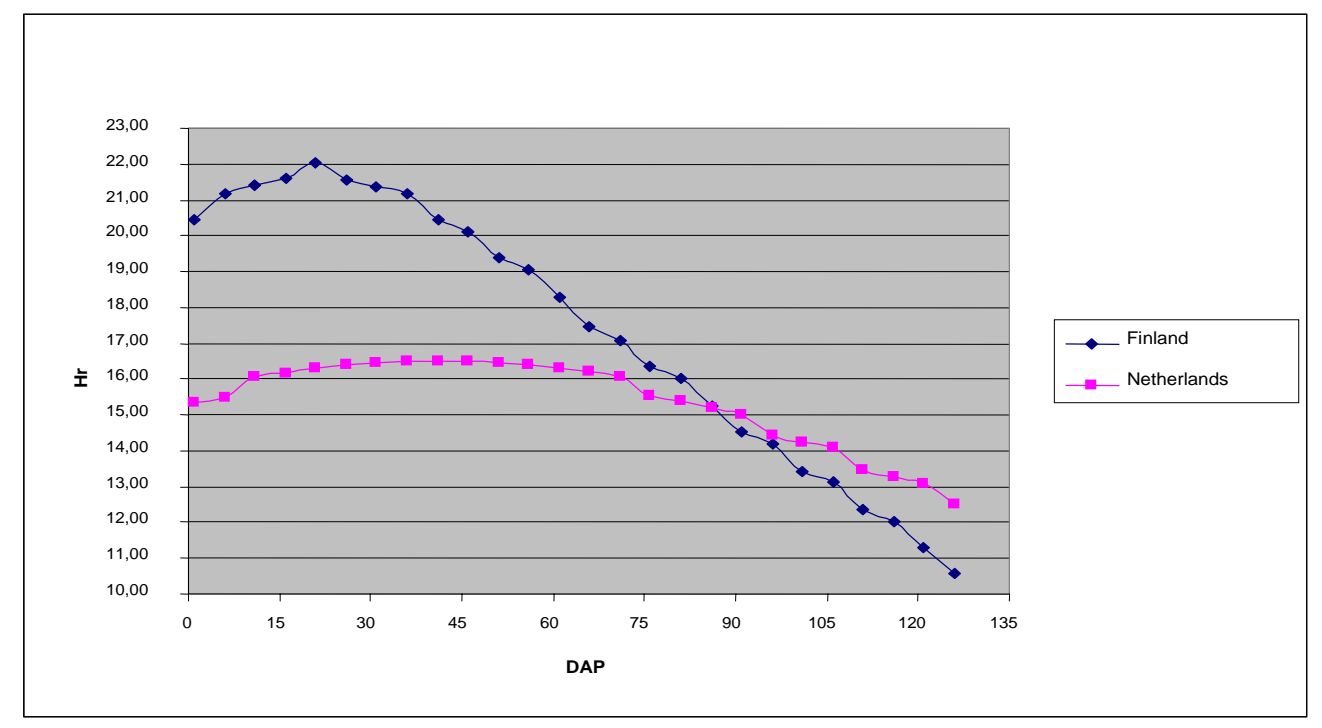

Figure 1. Differences in day length (hours of light) during the growing season in Finland and in the Netherlands. The day length is presented by days after planting (DAP). 
The experimental design for field experiment in Finland followed the one in the Netherlands. Each genotype with 3 individuals from the $\mathrm{CxE}$ population was randomised within 8 blocks. The blocks from 1 to 7 were harvested with start on 30 days after planting (DAP) in approximately 7 days intervals. Block 8 was harvested in four steps from 112 DAP after the senescence of the individual genotypes. Each of the blocks included also 20 control varieties, with 3 individuals (altogether 60 control plants). The experiments were managed by using standard potato cultivation methods of the respective experimental site. The most important environmental factor differing between the experimental sites was the day length during the growing season (Figure 1.). All the evaluations were conducted on all the three individuals of each genotype and the control varieties. Altogether, eighteen developmental traits were measured (Table 1).

Table 1. Developmental traits of the (CxE) potato population evaluated in the very long-day field trial experiment in Finland in 2004. Evaluated characteristics present both above and below ground traits.

\begin{tabular}{|c|c|c|c|}
\hline Evaluated trait & Description & Evaluated trait & Description \\
\hline 1. Date of emergence & $\begin{array}{l}\text { The days from planting to } \\
\text { emergence (DAP) }\end{array}$ & $\begin{array}{l}\text { 10. Degree of stolon } \\
\text { branching } \\
\text { (scale) }\end{array}$ & $\begin{array}{l}\text { Scale } 1-5(1=\text { no } \\
\text { branching, } 5=\text { more than } \\
20 \text { branches })\end{array}$ \\
\hline 2. Number of main stems & $\begin{array}{l}\text { Stems emerging directly } \\
\text { from the seed tuber }\end{array}$ & $\begin{array}{l}\text { 11. Number of swollen } \\
\text { stolon tips (stolon forming } \\
\text { tubers) }\end{array}$ & $\begin{array}{l}\text { A tuber was defined as } \\
\text { swollen tip with at least } 12 \\
\text { mm in diameter. }\end{array}$ \\
\hline 3. Number of wild stems & $\begin{array}{l}\text { Stems with leaves that } \\
\text { started as stolons followed } \\
\text { by a switch to orthotropic } \\
\text { growth }\end{array}$ & $\begin{array}{l}\text { 12. Position of swollen } \\
\text { stolon tips and growing } \\
\text { tubers }\end{array}$ & $\begin{array}{l}\text { Stolon tip, on a stolon side } \\
\text { branch, as part of a chain } \\
\text { on the stolon, or other } \\
\text { locations }\end{array}$ \\
\hline 4. Plant height $(\mathrm{cm})$ & $\begin{array}{l}\text { Length of the highest stem } \\
\text { from the ground level to } \\
\text { the main apex }\end{array}$ & $\begin{array}{l}\text { 13. Secondary tuber } \\
\text { growth (scale) }\end{array}$ & Scale $1-5$ \\
\hline $\begin{array}{l}\text { 5. Flower colour (for } \\
\text { control of the genotype) }\end{array}$ & $\begin{array}{l}\text { White, red violet, blue } \\
\text { violet, light blue or other } \\
\text { possible colours }\end{array}$ & $\begin{array}{l}\text { 14. Tuber size distribution } \\
(\mathrm{mm})\end{array}$ & $\begin{array}{l}\text { Each tuber larger than } 12 \\
\text { mm in diameter was } \\
\text { recorded. }\end{array}$ \\
\hline 6. Flowering (scale) & $\begin{array}{l}\text { Scale from 1-7 (1 = first } \\
\text { open flower, } 4=\text { peak of } \\
\text { flowering, } 7=\text { end of } \\
\text { flowering). }\end{array}$ & $\begin{array}{l}\text { 15. Total tuber weight per } \\
\text { plant (g) }\end{array}$ & \\
\hline 7. Senescence (scale) & $\begin{array}{l}\text { Scale } 1 \text { to } 7 \text { ( } 1=\text { first } \\
\text { yellow leaves, } 7=\text { no } \\
\text { green tissue left) }\end{array}$ & $\begin{array}{l}\text { 16. Quality of root system } \\
\text { (scale) }\end{array}$ & $\begin{array}{l}1=\text { poor, } 2 \text { = normal, } 3= \\
\text { very long and dense }\end{array}$ \\
\hline 8. Number of new stolons & $\begin{array}{l}\text { Count of all the stolons } \\
\text { that do not show signs of } \\
\text { tip swelling }\end{array}$ & $\begin{array}{l}\text { 17. Length of root system } \\
(\mathrm{cm})\end{array}$ & \\
\hline $\begin{array}{l}\text { 9. Length of the longest } \\
\text { stolon }(\mathrm{cm})\end{array}$ & & $\begin{array}{l}\text { 18. Incidence of } \\
\text { Streptomyces scabies and } \\
\text { Rhizoctonia } \\
\text { solani }\end{array}$ & $\begin{array}{l}\text { Visual inspection of the } \\
\text { harvested tubers }\end{array}$ \\
\hline
\end{tabular}

The statistical analyses were carried out with the SPSS 12.0 program. The data was tested for outliers, and if found, they were excluded from the calculations. All the traits were tested for normality and when needed transformed (square root or log10 transformation). Descriptive statistics e.g. means, standard deviation, minimum and maximum of the CE population, for different traits were calculated. Bivariate 2-tailed Pearson-Correlation was used to calculate correlation between different traits both for the Finnish and Dutch data. When needed the data from the Netherlands was also transformed (log transformation) to fit the data from Finland in the correlation test.

For generation of AFLP markers 15 EcoRI/MseI based primer combinations were used, and the markers were visually scored as presence or absence of the band. The linkage analysis was performed according to the double pseudo-testcross approach for cross pollinating populations and using the 
software JoinMap 2.0. The 403 markers obtained from the AFLP analysis, were used to construct a maternal (C) and a paternal (E) maps with 12 linkage groups each. The C map consisted of 140 markers spanning $919 \mathrm{cM}$ and the E map consisted of 178 markers spanning $784 \mathrm{cM}$. In order to identify if the origin of the map each linkage group is preceded by the letter $\mathrm{C}$ or $\mathrm{E}$, followed by the linkage group number (Celis-Gamboa 2002).

For the QTL analysis the data was evaluated at first for normality with normal Q-Q plotproportion estimation formula according to Blom (1958). Rank assigned to ties: Mean, which showed the correlation between the normal expected values to the observed values, and when needed the data was transformed. Differences between genotypes were evaluated using univariate analysis, and the mean values for each genotype obtained from the univariate test were used in the QTL analysis. Since the maternal (C) and the paternal (E) maps could not be integrated unambiguously, due to the low informative value of the dominantly scored 3:1 AFLP "bridge" markers, QTL mapping was performed on the separated $\mathrm{C}$ and $\mathrm{E}$ parental maps.

Using the software package MapQTL version 5.0 (Van Ooijen, 2004), the mean values of normally distributed quantitative traits were first analysed by interval mapping. The program was set to calculate in steps of $5 \mathrm{cM}$ between the linkage markers and the criteria for detecting QTL with significance level of 0.05 , was defined for threshold LOD value of 3.0, after performing a permutation test, as implemented in MapQTL version 5.0. In the next step cofactors were tested according to the results obtained from the interval mapping. Using the automatic cofactor selection options, all the markers with LOD values larger or close to 3.0, were tested. The selected cofactors were then used to run the multiple-QTL model test, which gave rise to more accurate peak locations. To obtain 95\% confidence interval around the estimated point, a so called two-LOD support interval was constructed, by taking the two positions, left and right to the peak, that had a LOD value of two less than the maximum. All the identified QTLs, were compared to the QTLs identified in the CxE population grown in the Netherlands.

\section{Results and discussion}

\section{The dynamics of the CxE population development in Finland}

Highly significant differences $(\mathrm{P}<0,01)$ were found between the genotypes for the traits evaluated. In Figure 2. developmental patterns of the CxE population in Finland are demonstrated.

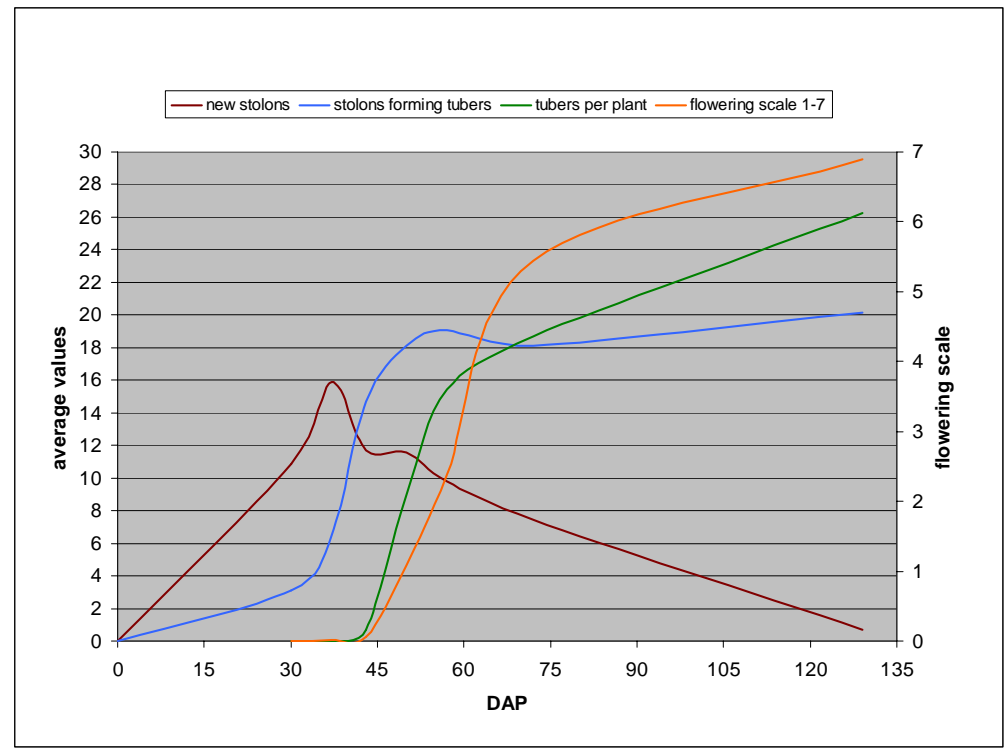

Figure 2. A general view of the development of the CxE population in Finland.

The main features of the developmental processes on the population level were the formation of stolons and tuber incipients, as well as the start of stolon branching, well before start of flowering. In the corresponding experiment in the Netherlands these processes occurred somewhat later in relation to flowering (Celis-Gamboa et al. 2002). Initiation of stolon swelling (10 days difference) and 
emergence of first tuber incipient (7 days) in the varieties took place on average 10 days earlier than in the CxE clones (Zaban 2005).

\section{Association between flowering and tuberization}

In the Netherlands 30\% of the CE population had swollen stolon tips before, 34\% simultaneously with and 36\% after the first flower was opened. In Finland the corresponding values were 71, 21 and $8 \%$ (Figure 3). In the Netherlands most of the CE population started flowering between 36 and 42 DAP, and the mean for onset of flowering for all the varieties was on 42 DAP, while in Finland the mean onset for flowering for CxE population was 50 DAP. No correlation was found between the onset of flowering (DAP) in Finland and the onset of flowering (DAP) in the Netherlands ( $r=-0,039)$. These results indicate contrary to earlier studies (reviewed by O'Brien et al. 1998) that the initiation of stolon tip swelling is not dependent on the onset of flowering. However, no conclusions on the relationship between tuber induction and flowering can be drawn from our data. More information on this aspect has been gathered in the field experiment of the growing season 2005.

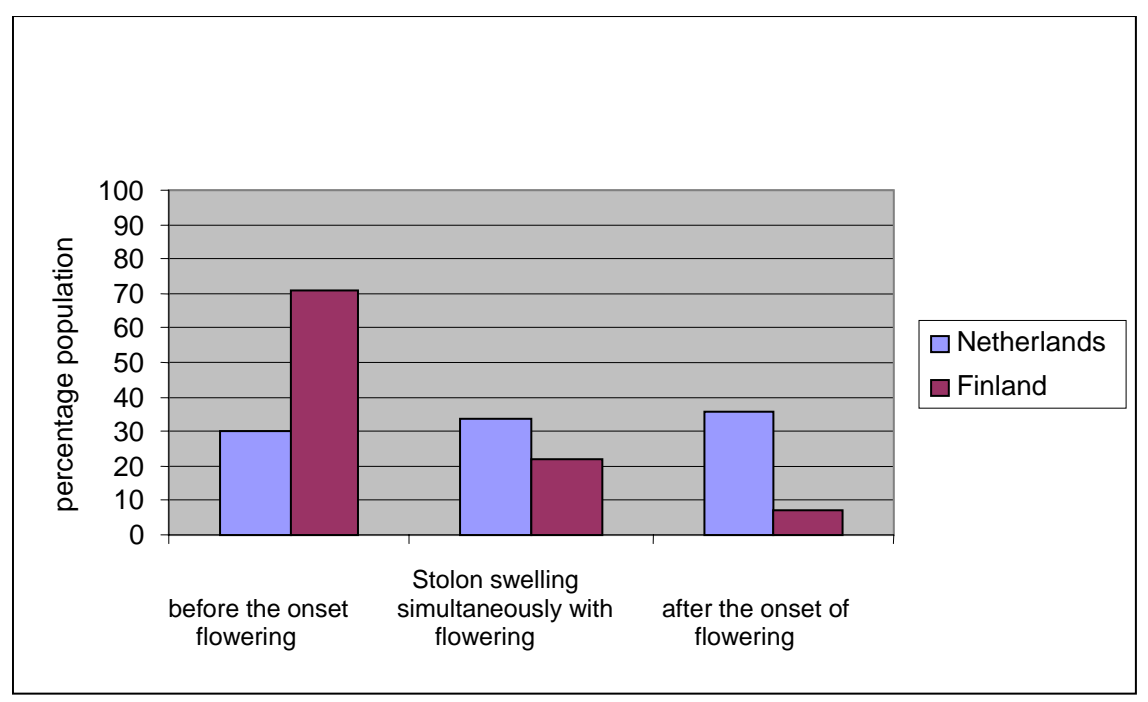

Figure 3. Relationship between flowering and tuber initiation in Finland and the Netherlands.

\section{QTLS}

As a result of QTL analyses a QTL associated with tuber formation was identified on chromosome E5, and QTLs associated with stolon characteristics were identified on chromosomes E1, E4, E10 and E12 (Table 2).

All the QTLs identified both in Finland and in the Netherlands were compared to examine if they share similar locations. Figure 4 illustrates schematically QTLs detected in the chromosome e5. The results may indicate that the traits are, at least partially, interrelated and are controlled by the same genes (Simko et al. 1999). The same QTL as identified for the number of stolon forming tubers at 37 and 43 DAP on chromosome e5, was found in the Netherlands associated (with very high LOD values) to the duration of plant life cycle, onset of senescence, mid point of senescence and plant maturity type (the population was classified in categories according to the duration of the plant life cycle) (Celis-Gamboa 2002). Another trait from the Netherlands, which had the same QTL as the trait for number of stolon forming tubers at 37 and 43 DAP, was the number of tubers per plant. The QTL identified in Finland to the number of stolon forming tubers at 50 DAP, was associated in the Netherlands to the duration of plant cycle and the duration of senescence. Also the QTL results on tuber formation obtained in this study are in agreement with earlier studies (Van den Berg et al. 1996, Schäfer-Pregl et al. 1998, Simko et al. 1999), a fact that confirms the relevancy of the data collected. 
Table 2. QTLs identified for the degree of stolon branching and for the length of the longest stolon in the field trial in Finland.

\begin{tabular}{|l|l|l|l|l|}
\hline \multirow{3}{*}{ Trait } & \multicolumn{3}{|l|}{ QTLs information } & \\
Chrom. & Position & LOD & Marker \\
\hline Stolon branching 50 DAP & e4 & 53.1 & 4.52 & E39/M60-42e4 \\
\hline Stolon branching 72 to 129 DAP & e4 & 52.1 & 9.21 & E32M50-206e4 \\
\cline { 2 - 5 } & e10 & 75.5 & 3.12 & E32M54-74e10 \\
\cline { 2 - 5 } & e12 & 51.7 & 3.49 & E39/M60-9e12 \\
\hline \multirow{3}{*}{ Stolon length 50 DAP } & e1 & 16.4 & 4.24 & E38/M59-431e13 \\
& & 30.1 & 5.7 & E32M61-18e13 \\
\cline { 2 - 5 } & e4 & 52.1 & 4.82 & E32M50-206e4 \\
\hline Stolon length 72 to 129 DAP & e1 & 16.4 & 4.02 & E38/M59-431e13 \\
& & 30.1 & 4.83 & E32M61-18e13 \\
\cline { 2 - 5 } & e4 & 54.6 & 9.4 & E32M50-105e4 \\
\cline { 2 - 5 } & e12 & 59.2 & 3.09 & E32M50-97e12 \\
\hline
\end{tabular}

e5

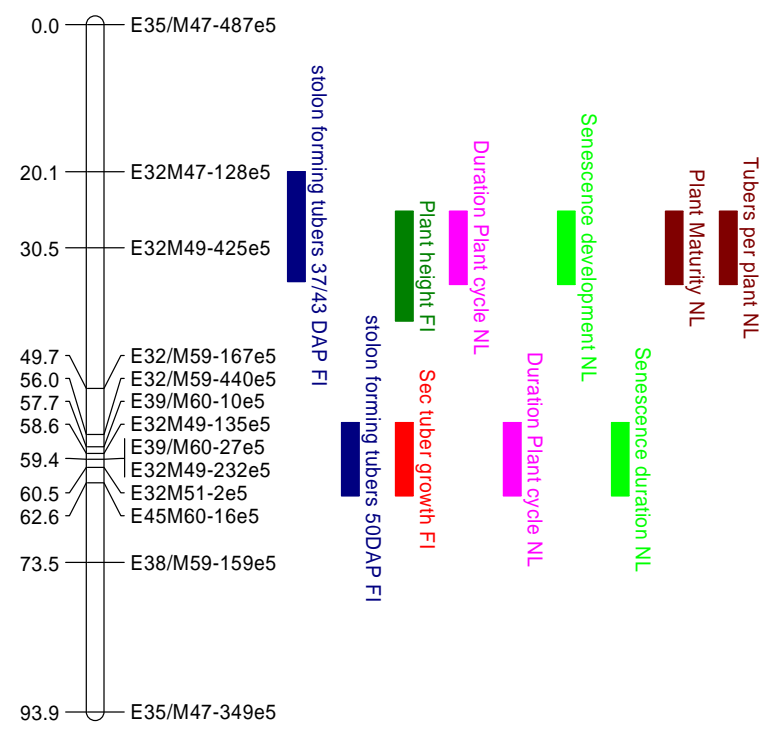

Figure 4. Schematic overview of QTLs detected on chromosome e5 in Finland and the Netherlands. Indicated are the QTL peak positions and an arbitrary QTL support interval of $5 \mathrm{cM}$ on both sides of the peak position.

\section{Conclusions}

It is well known that repeated QTL mapping studies, using identical materials in different environments or years will give varying results. This is due to the limited power of detection of QTLs in practically manageable population sizes, which, together with random experimental effects can cause a different subset of the genetic effects present in the population to manifest itself in each single analysis, especially for smaller effect factors that just surpass the detection limit. This is why repetition of experiments is essential to identify true factors that underlie traits of interest from onetime analysis artefacts. 
As a conclusion, this is the first time that the effects of environmental conditions and especially different day length on potato development can be followed and compared. This work has been possible due to the use of the same potato population, molecular marker map and field trials established in the Netherlands and in Finland. The preliminary results obtained in this study (mainly from Finland from one growing season 2004) and the already existing data from the experiment in the Netherlands provide a good basis for determining the influence of different environmental conditions on potato development. More accurate analyses will be realised when the data collected from the follow-up field experiment in Finland 2005 has been analysed. Already the preliminary data achieved indicates interesting associations between tuber initiation and onset of flowering and some common, thus meaningful, QTLs in data from obtained in Finland and the Netherlands. Further QTL analyses including those from S America will provide better understanding of the genetics of complex characters during potato development and, furthermore, will lead to the improvement of the potato crop via breeding programs.

\section{References}

Blom, G. 1958. Statistical estimates and transformed beta variables. John Wiley and Sons, New York, N. Y., 68$75,143-146$.

Celis-Gamboa, C. 2002. The life cycle of the potato (Solanum tuberosum L.): From crop physiolog to genetics. Ph.D. Thesis, Wageningen University. 191 pp.

Celis-Gamboa, C., Struik, P.C , Jacobsen, E., Visser, R.G.F. 2003. Sprouting of seed tubers during cold storage and its influence on tuber formation, flowering and the duration of the life cycle in a diploid population of potato. Pot Res 46:9-25.

Celis-Gamboa, C., Struik, P., Jacobsen, E. \& Visser, R.G.F. 2003. Temporal dynamics of tuber formation and related processes in a crossing population of potato (Solanum tuberosum). Annals of Applied Biology 143: 175-187.

Driver, C. M. and Hawkes, J. G. 1943. Phtoperiodism in the potato. Imperial Bulletin Plant Breeding and Genetics, Cambridge, England. Technical Communication.

Ewing, E. E. 1978. Critical photoperiod for tuberization: a screening technique with potato cuttings. American Potato Journal 55: 43-55.

Khedher, M. B. and Ewing, E.E. 1985. Growth analysis of eleven potato cultivars grown in the greenhouse under long photoperiods with and without heat stress. The American Potato Journal 62: 537-554.

Martinez-Garcia, J. F., Garcia-Martinez, J. L., Bou, J. and Prat, S. 2002. The interaction of gibberellins and photoperiod in the control of potato tuberazation. Journal of Plant Growth Regulation 20: 377-386.

Mendoza, H. A. and Haynes, F.L. 1976. Variability for photoperiodic reaction among diploid and tetraploid potato clones from three taxonomic groups. American Potato Journal 53: 319-333.

O'Brien, P.J., Allen, E.J. and Firman, D.M. 1998. A review of some studies into tuber initiation in potato (Solanum tuberosum) crops. Journal of Agriculture Science 130: 251-270.

Regel, P. A. and Sands, P. J. 1983. A model of the development and bulking potatoes (Solanum tuberosum L.). IV. Daylength, plant density and cultivar effects. Field Crops Research 6: 349-364.

Schäfer-Pregl, R., Ritter, E., Concilio, L., Hesselbach, J., Lovatti, L., Walkemeier, B., Thelen, H., Salamini, F. and Gebhardt, C. 1998. Analysis of quantitative trait loci (QTLs) and quantitative trait alleles (QTAs) for potato tuber yield and starch content. Theoretical and Applied Genetics 97: 834-846.

Simko, I., Vreugdenhil, D., Jung, C.S. and May, G.D. 1999. Similarity of QTLs detected for in vitro and greenhouse development of potato plants. Molecular Breeding 5: 417-428.

Van den Berg, J.H., Ewing, E.E., Plaisted, R.L., McMurry, S. and Bonierbale, M.W. 1996. QTL analysis of potato tuberization. Theoretical and Applied Genetics 93: 307-316.

Van Ooijen J.W. 2004. MapQTL 5, Software for the mapping of quantitative trait loci in experimental populations. Kyazma bv, Wageningen, The Netherlands (www.kyazma.nl).

Werner, H. O. 1942. Relative response of several varieties of potatoes to progressively changing temperatures and photoperiods controlled to simulate "northern" and "southern" conditions. The American Potato Journal 19: 30-40.

Zaban, A. 2005. Comparison of developmental patterns and specific QTLs of the genetically broad based potato population between Northern Finland and the Netherlands. M. Sc. Thesis, Oulu University. 75 pp. 